\title{
THE LONG-TERM FOLLOW-UP OF PATIENTS TREATED WITH YAG LASER TO RE-OPEN CLOSED OR CLOSING FISTULAE FOLLOWING GLAUCOMA SURGERY
}

\author{
TILAK V. DE ALWIS \\ Aylesbury
}

\begin{abstract}
SUMMARY
The Q-switched neodymium:YAG laser was used to reopen closed or closing fistulae following surgery for glaucoma. Before laser treatment the cause of the obstruction of the fistula was located using a gonioscope. Following laser treatment a significant lowering of the intraocular pressure was seen with minimal complications, which has been maintained over a period of 5 years.
\end{abstract}

Trabeculectomy is the surgical treatment of choice in chronic open and closed angle glaucomas. Follow-up studies have shown that the intraocular pressure is controlled in $80 \%$ of these eyes following trabeculectomy. ${ }^{1}$ The failure to control the intraocular pressure in the remainder is due to resistance to aqueous outflow at the internal opening of the sclerostomy, conjunctiva or at the episclera. ${ }^{2}$ Previous studies have shown that the causative factors interfering with the outflow of aqueous at the sclerostomy site are (1) hyaline plugs in the inner stoma of the sclerostomy, ${ }^{3}(2)$ iris incarceration at the sclerostomy ${ }^{4}$ and (3) complete sealing of the sclerostomy due to fibrosis. ${ }^{4}$ In a series of patients who had failed trabeculectomies the factors responsible for failure to drain the aqueous were identified, and eliminated using the YAG laser.

\section{MATERIALS AND METHODS}

The patients who attended the outpatient department following trabeculectomy and who had raised intraocular pressure were examined with a gonioscope to assess the sclerostomy. If an obstructive cause such as hyaline plugs, iris incarceration or fibrosis at the internal opening of the sclerostomy was found, the patient was entered into the study. Raised intraocular pressure in the absence of an obstructive cause at the sclerostomy site was considered to be due to other factors not relevant to the present study and such patients were excluded.

The pre-operative evaluation of patients is given in

Correspondence to: Mr. T. V. De Alwis, FRCS Eng, FCOphth, DO, Eye Unit, Stoke Mandeville Hospital, Aylesbury, Bucks. HP21 8AL, UK.
Table I. The instrument used in the study was the Q-switched neodymium:YAG laser (Lasag, Switzerland). A specially designed gonioscopy lens (CGA 1.4) was utilised for lasering.

The cornea was anaesthetised using amethocaine eye drops (one drop repeated four times) and the gonioscopy lens filled with hydroxymethylcellulose was placed on the cornea. The internal ostium of the sclerostomy was visualised and the lasering was commenced. The average laser energy used was $4 \mathrm{MJ}$ and the average number of laser applications was 25 (Table II). No attempt was made to perforate the scleral flap.

The lasering was stopped once the incarcerated iris or the hyaline plugs had been removed. At the end of the laser treatment the intraocular pressure was recorded. Patients were advised to use prednisolone sodium phosphate eye drops $0.5 \%$ three times a day for 1 week and the current antiglaucoma therapy was discontinued. The follow-up visits were arranged for 1 week, 4 weeks, 3 months, 6 months and annually.

At the follow-up visits the following details were recorded: (1) visual acuity, (2) intraocular pressure, (3) state of the internal ostium of the sclerostomy and the state of the bleb, and (4) central visual fields, plotted with an octopus perimeter using program 36 (Table III).

Table I. Clinical data

\begin{tabular}{lccclc}
\hline Diagnosis & Sex & $\begin{array}{c}\text { Age } \\
\text { (yr) }\end{array}$ & $\begin{array}{c}\text { Visual } \\
\text { acuity } \\
\text { (Snellen) }\end{array}$ & $\begin{array}{c}\text { Gonioscopy } \\
\text { findings }\end{array}$ & $\begin{array}{c}\text { Pre-laser } \\
\text { IOP } \\
\text { (mmHg) }\end{array}$ \\
\hline COAG & M & 74 & $6 / 18$ & Hyaline plug & 40 \\
COAG & M & 65 & $6 / 18$ & Incarcerated iris & 24 \\
COAG & $\mathrm{F}$ & 56 & $6 / 9$ & Hyaline plug & 33 \\
COAG & $\mathrm{F}$ & 70 & $6 / 9$ & Incarcerated iris & 30 \\
COAG & $\mathrm{F}$ & 59 & $6 / 12$ & Complete fibrosis & 26 \\
COAG & $\mathrm{M}$ & 78 & $6 / 9$ & Incarcerated iris & 54 \\
COAG & $\mathrm{M}$ & 70 & $6 / 9$ & Hyaline plug & 26 \\
CACG & $\mathrm{F}$ & 45 & $6 / 9$ & Hyaline plug & 40 \\
COAG & $\mathrm{F}$ & 74 & $6 / 9$ & Incarcerated iris & 24 \\
COAG & $\mathrm{F}$ & 68 & $6 / 9$ & Incarcerated iris & 38 \\
COAG & $\mathrm{M}$ & 72 & $6 / 6$ & Incarcerated iris & 40 \\
\hline
\end{tabular}

COAG, chronic open angle glaucoma; CACG, chronic angle closure glaucoma; M, male; F, female; IOP, intraocular pressure. 
Table II. Treatment and results

\begin{tabular}{lcccc}
\hline $\begin{array}{l}\text { Laser } \\
\text { shots }\end{array}$ & $\begin{array}{c}\text { Laser } \\
\text { energy }\end{array}$ & $\begin{array}{c}\text { T-to-L } \\
\text { interval } \\
(\text { weeks })\end{array}$ & $\begin{array}{c}\text { Pre-laser } \\
\text { IOP } \\
(\mathrm{mmHg})\end{array}$ & $\begin{array}{c}\text { Final } \\
\text { IOP } \\
(\mathrm{mmHg})\end{array}$ \\
\hline 25 & $3 \mathrm{MJ} / 2$ pulses & 4 & 40 & 16 \\
28 & $4 \mathrm{MJ} / 3$ pulses & 4 & 24 & 16 \\
30 & $5 \mathrm{MJ} / 3$ pulses & 6 & 33 & 15 \\
24 & $3 \mathrm{MJ} / 2$ pulses & 3 & 30 & 16 \\
22 & $4 \mathrm{MJ} / 3$ pulses & 28 & 26 & 26 \\
22 & $4 \mathrm{MJ} / 3$ pulses & 4 & 54 & 18 \\
24 & $4 \mathrm{MJ} / 3$ pulses & 5 & 26 & 15 \\
28 & $4 \mathrm{MJ} / 3$ pulses & 4 & 40 & 12 \\
26 & $5 \mathrm{MJ} / 3$ pulses & 6 & 24 & 18 \\
25 & $4 \mathrm{MJ} / 2$ pulses & 7 & 38 & 18 \\
26 & $5 \mathrm{MJ} / 3$ pulses & 6 & 40 & 20 \\
\hline
\end{tabular}

T-to-L interval, trabeculectomy-to-laser interval; IOP, intraocular pressure.

\section{RESULTS}

At the final follow-up 10 of 11 eyes had an intraocular pressure of less than $20 \mathrm{mmHg}$ (range 12-20 $\mathrm{mmHg}$ ) without antiglaucoma therapy (Table II). The single case of failure had dense fibrosis of the sclerostomy.

The complications noticed at the time of treatment were microscopic hyphaema in 4 eyes (4/11) and mild ocular pain in 5 eyes $(5 / 11)$. No increase in intraocular pressure was noticed in any patient immediately after laser therapy.

The mean pre-laser intraocular pressure was 34.0 $\mathrm{mmHg}$, which fell to $16.4 \mathrm{mmHg}$ after laser treatment. This difference is statistically significant $(p=0.005)$. The mean pre-laser score for the central visual fields on the octopus perimeter was 1290 decibels and the mean score at final follow-up at 5 years was 1267 decibels (Table III). This difference was not statistically significant $(p=0.5)$.

\section{DISCUSSION}

The neodymium:YAG laser when used in its Q-switched mode produces ultrashort high-power pulses which have an effect on the tissues at its point of focus like a microexplosion..$^{5}$ An optical breakdown of the tissues occurs, with the reflection of the shock waves anteriorly producing a visible cutting effect. ${ }^{6}$

The YAG laser has been used successfully in the past to control intraocular pressure through transcleral cyclocoagulation. ${ }^{7}$ More recently it has been used to open failed or failing trabeculectomies, successfully lowering the intraocular pressure. ${ }^{8,9}$ The average duration of follow-up of these patients was 10.7 months in one study and 9 months in the other, and the only criterion for success was the sustained lowering of the intraocular pressure. In the present study two criteria were used to define success: sustained lowering of intraocular pressure and absence of deterioration of visual fields. All 10 patients were followed for periods ranging from 54 months to 60 months. There was successful control of the intraocular pressure without further medication and there was no increased visual field loss during this period. The single case that failed to respond to laser treatmnent had dense fibrosis of the sclerostomy, and in this patient the interval between the primary surgical procedure and the laser therapy was
Table III. Field analysis

\begin{tabular}{lcc}
\hline $\begin{array}{l}\text { Patient } \\
\text { no. }\end{array}$ & $\begin{array}{c}\text { Central fields } \\
\text { before laser }(\mathrm{db})\end{array}$ & $\begin{array}{c}\text { Central fields } \\
\text { after laser }(\mathrm{db})\end{array}$ \\
\hline 1 & 1016 & 1010 \\
2 & 1180 & 1170 \\
3 & 1300 & 1250 \\
4 & 1350 & 1250 \\
5 & 1400 & - \\
6 & 1400 & 1400 \\
7 & 1480 & 1470 \\
8 & 1400 & 1400 \\
9 & 1200 & 1200 \\
10 & 1280 & 1250 \\
11 & 1300 & \\
\hline
\end{tabular}

Patient no. 5 was taken out of the study as he did not respond to laser treatment.

28 weeks. The mean interval between the primary surgical procedure and the laser therapy for the successful patients was 4.9 weeks. There was no correlation between the status of the bleb and the intraocular pressure at 5 years. Four patients had cystic blebs and lower intraocular pressure and 6 patients had no blebs and lower intraocular pressure.

\section{CONCLUSIONS}

In all patients with failed or failing trabeculectomies a thorough examination of the anterior segment of the eye with slit lamp biomicroscopy and gonioscopy is of paramount importance. The early recognition of iris incarceration in the sclerostomy or hyaline plugs at the sclerostomy mean laser therapy should be successful. As the complications seen were minimal and the success rate high, YAG laser is a useful line of treatment for selected cases of failed trabeculectomy.

Key words: Failed trabeculectomy, Glaucoma, YAG laser.

\section{REFERENCES}

1. Watson PG. When to operate on open angle glaucoma. Eye $1987 ; 1: 51-4$

2. Hitchings RA, Grierson I. Clinicopathological correlation in eyes with failed fistulizing surgery. Trans Ophthalmol Soc UK 1986;103:84-8.

3. Watson PG, Barnet F. Effectiveness of trabeculectomy in glaucoma. Am J Ophthalmol 1975;79:831-45.

4. Parrish RK. Duane's clinical ophthalmology, vol. 5. Philadelphia: Lippincott, 1989:1-48.

5. Frankhauser F, Vanderzypen E. Future of laser in ophthalmology. Trans Ophthalmol Soc UK 1982;102:159-63.

6. Mcallister JA, Schawarly LW, Moster M, Spaeth GL. Laser peripheral iridectomy comparing Q switched neodymium with argon laser. Trans Ophthalmol Soc UK 1985;104:67-9.

7. Badeep O, Trópe GE, Mortimer C. Short term effects of neodymium:YAG transcleral cyclocoagulation in patients with uncontrolled glaucoma. Br J Ophthalmol 1988;72:615-7.

8. Cohn HC, Whalen WR, Aron-Rosa D. YAG laser treatment in failed trabeculectomies. Am J Ophthalmol 1989;108: 395-403.

9. Dailey RA, Samples JR, Vanbuskirk EM. Reopening of filtration fistulas with the neodymium:YAG laser. Am J Ophthalmol 1986;102:491-5. 